\title{
Prospective Study in Tertiary Care Hospital for Osteoarthritis Patients in Rural Area of Haryana
}

\author{
Arun Arora', Rita Kumari', Sumeet Gupta 1,*, Manjeet Singh ${ }^{2}$ \\ ${ }^{1}$ Department of Pharmacology and Clinical Practice, MM College of Pharmacy, MM (Deemed to be University), Mullana, Ambala, Haryana, INDIA \\ 2Department of Orthopedics, MM Institute of Medical Science and Research, Mullana, Ambala, Haryana, INDIA.
}

\begin{abstract}
Objectives: The objective of this study was to compare clinical outcomes of Nonsteroidal anti-inflammatory drugs as monotherapy and combinational therapy with glucosamine in osteoarthritis patients. Methods: A randomized prospective observational study was conducted between December 2018 and June 2019 at M. M. Institute of Medical Science and Research. Total 360 patients were recruited and were divided into four different groups. Patients received selective cyclooxegenase-2 inhibitor with and without glucosamine sulphate and non-selective cyclooxegenase-2 inhibitor with and without glucosamine sulphate. The primary outcomes were measured by liquesce index score and visual analogue scale at $2^{\text {nd }}$ and $4^{\text {th }}$ week. Results: Bodyweight and the age were found statistical significant among different groups. Both the combination treatment groups were statistical significant potent than individual treatment group after the four weeks of treatment. Statistical significant results were found in both liquesce index
\end{abstract}

(LI) and Visual Analogues Score (VAS). Conclusion: Marked improvement was observed in both the scores (Lequesne index and Visual Analogues) after four weeks of treatment and it would be better therapy in both the combination with Glucosamine than individual for osteoarthritis patient. Key words: Cyclooxegenase-2 inhibitor, Follow up treatment, Glucosamine sulphate, Inflammation, Rheumatology, Visual Analogues Score.

\section{Correspondence}

Dr. Sumeet Gupta

Professor, MM College of Pharmacy, M. M. (Deemed to be University), Mullana, (Ambala), Haryana, INDIA

Phone: +91 9872620252

Email: sumeetgupta25@gmail.com

DOI: 10.5530/jyp.2020.12.75

\section{INTRODUCTION}

Osteoarthritis is the uncontrollable rheumatic disease which is generally characterized by local inflammation, pain and stiffness in joints, tenderness and limitation of movements. Osteoarthritis generally involves morphological as well as biochemical changes at synovial membrane leads to hypertrophy and white tissue loss near bones. ${ }^{1-3}$ Most common site in the joints are hands, knees, spine, feet and also commonly in hip and shoulder joints. Aging is also one of the factors which give $80 \%$ the patients induce osteoarthritis. Life style is also one of the important aspect which can be induces risk for osteoarthritis like weight gain, absence of activity, work related damage, hereditary predisposition, injury and gender. ${ }^{4}$ Stiffness is common problem in the morning when these patients do routine activities. This is due to damage of cartilage which leads to friction of joints and crunching or clicking sound observe during its movement. ${ }^{5-7}$ Globally, population of America and Europe reflects highest prevalence of Osteoarthritis. ${ }^{8}$ Gender wise, it is almost $9.6 \%$ male and $18 \%$ of females of above age 60 years are reported with symptomatic osteoarthrtitis. ${ }^{9-10}$ The European League against Rheumatism reports $30 \%$ population over 65 years of age with radio-graphic proof of knee osteoarthritis. ${ }^{11}$ Osteoarthritis is the second most common rheumatologic problem in India with prevalence of $22 \%$ to $39 \%$. In India, female is more prone risk to osteoarthritis than male. Nearly $45 \%$ of women over the age of 65 years have symptoms while radiological evidence is found in $70 \%$ of those over 65 years. According to study reported on Asian countries revealed that $13.7 \%$ prevalence in rural areas than $6.9 \%$ in rural areas. In one of the Indian study reported that $56.6 \%$ have osteoarthritis in rural region than $32.6 \%$ in urban region. ${ }^{12,13}$
Treatment under lifestyle modification and drug regimen are also not fully supported to treat this disease. ${ }^{14,15}$ Various drugs include Nonsteroidal anti-inflammatory drugs (NSAIDS), opoids analgesics, intra-articular agents and topical agents. Paracetamol is the first initial drug treatment to prescribe with other lifestyle modification. Nonsteroidal anti-inflammatory drugs and salicylates are prescribed for second choice when the patient does not relief from pain. ${ }^{16,17}$ Side effects are also concern regarding anti osteoarthritis drug therapy. So, for better gastro intestinal tolerability, Cyclooxegenase-2 inhibitors (Cox-2) can be considered for the patient. Non-selective non steroidal anti inflammatory like etoricoxib (60 mg/day), valdecoxib (10 mg/ day) and celecoxib (60 mg/day) are more efficacious as pain reliever. In combination of paracetamol and opioids (codeine) give better drug therapy than paracetamol alone. ${ }^{18-20}$

However, ongoing studies are evaluates for maintaining cardiovascular patients with cyclooxegenase- $2 .^{21}$ Glucosamine sulfate (GS) is a subordinate of the naturally occurring amino monosaccharide glucosamine present in synovial liquid and joint cartilage. Glucosamine was proposed as a slow acting drug in treatment of osteoarthritis ${ }^{21,22}$ It act as stimulator for proteoglycan synthesis by cultivated human chondrocytes on articular cartilage. ${ }^{23-25}$ Two randomized controlled trial with twofold blinded study conducted in Belgium ${ }^{26}$ and Czech Republic ${ }^{27}$ which proposed that, this medication ( $1.5 \mathrm{~g}$ day by day) has a considerable indication and structure changing impact in patients with mild to moderate osteoarthritis of knee. The symptomatic efficacy of glucosamine in osteoarthritis has been analysed through high-quality quantitative systematic reviews. ${ }^{28-30}$ However, no study has directly compared the clinical outcomes and efficacy between monotherapy (i.e

This is an open access article distributed under the terms of the Creative Commons Attribution-NonCommercial-ShareAlike 4.0 License, which allows others to remix, tweak, and build upon the work non-commercially, as long as the author is credited and the new creations are licensed under the identical terms. 
NSAIDS or glucosamine) and a combination of the two drugs. Thus, we conducted the study to find out more effectiveness with individual therapy (Glucosamine sulphate or NSAIDS) or in combination therapy of these two.

\section{MATERIALS AND METHODS}

\section{Study design}

The study was approved from Institutional Ethics Committee (IEC1313, dated: 19.12.2018) and then planned for randomized, prospective observational study. The study was conducted between the period of December 2018 to June 2019 in Department of Orthopedics, Maharishi Markandeshwar Institute of Medical Science and Research.

\section{Study population}

Sample size was calculated on total population (approximately 30,000) around $30 \mathrm{~km}$, out of which 1600 people have osteoarthritis. A sample of 70 patients will be sufficient to represent the osteoarthritis population residing in the rural area under investigation. A questionnaire was prepared for recruitment which included the details of patients: Sociodemographic profile (age, sex, chief complaints, past history. any other disease), duration, x-ray report (standing Anterior-Posterior / Lateral/weight bearing/axial view) and symptoms were recorded. All patients were assessed for disease and pain severity by using validated and reliable Lequesne index ${ }^{28}$ and visual analogue scale and divided into four groups according to therapy.

Osteoarthritis patients were selected between the age of 30 years to 70 years shows the symptoms of knee pain and confirmed on the basis of radiographic evidence and clinical criteria were included in the study. Patients between the age of less than 30 years and more than 70 years had infectious disease, psychotic disorders; gastrointestinal disorder, knee surgery and other musculoskeletal disease were excluded out.

\section{Drug therapy for the patients}

A total 90 patients were recruited in each group by prospective method and received specific drug only in a given order. 1. Selective Cox-2 inhibitors (Celecoxib, trade name: Celebrex) 2. Selective Cox-2 inhibitors (Celecoxib) + Glucosamine sulphate $750 \mathrm{mg}$, b.d. (cartigen) 3 . Nonselective Cox-2 inhibitors (Diclofenac sodium, trade name: (Dilona forte) 4. Nonselective Cox-2 inhibitors (Diclofenac sodium, trade name: (Dilona forte) + Glucosamine sulphate $750 \mathrm{mg}$, b.d. (cartigen). Data was noted at $15^{\text {th }}$ day interval after the treatment.

\section{Outcome measures}

The primary outcomes were assured in the terms of lequesne index ${ }^{31}$ score and visual analogue scale. Scoring of both scales is measured at baseline and after the treatment at $2^{\text {nd }}$ and $4^{\text {th }}$ week. Lequesne is an algofunctional index used to asses scoring of patient. It is divided into 3 sections i.e. pain or discomfort having 5 questions (duration of stiffness, pain scoring during bed rest, walking, getting up), second section with 2 questions assessing score according to distance walked i.e. maximum distance walked $>1 \mathrm{~km}$ to $<100 \mathrm{~m},(0-6)$, third section of daily living activities (climb up, climb down, bend/squat, walking at unable ground) interpretation of LI is based on scoring in each section. Min. score- 0 and max score- 24 .

\section{Statistical Analysis}

Data analysis was done with the help of an SPSS version 14.5. Continuous variables are expressed as means $\pm \mathrm{SD}$. Intergroup comparisons are made using students $\mathrm{t}$ test using Turkey's range. $P$ value $\leq 0.05$ was considered statistically significant.

\section{RESULTS}

\section{Patient characteristics}

In our study, the prevalence rate of osteoarthritis in tertiary hospital was found to be $26.9 \%$. Our prospective study suggested that, total 1564 patients visited in outpatient department of orthopaedics in a period of 6 months, out of which 422 patients confirmed osteoarthritis patients. A total 90 patients in each group were enrolled in the study and randomly distributed to treatment groups. Baseline characteristics of patients and their distribution according to treatment groups are presented in Table 1. Female population was found to be more predominant in every group at the range of $70 \%$ to $90 \%$. i.e. $n=285 / 360$ when compared with male population which was only 75 cases out of 360 . Most of the patients visited at the age of 51-60 years. All four groups with respect to age were higher $(p<0.0001)$ statistical significant. Body weights were also higher statistical significant difference between all treated groups. Among cases, some of the patients developed prone to other risk diseases includes 24 patients had type 2 diabetes mellitus, 22 patients were hypertensive, one hypothyroidism and 46 were co associated with type 2 diabetes mellitus with hypertension during treatment. Maximum number of patients from all four groups had bilateral knee involvement (i.e. 84.4\%), followed by patients with right knee involved [i.e.11.6\%] and patients with left knee involved [ $n=3.8 \%]$. Patients showed duration of symptoms was not less than 3 months.

\section{Lequesne Index Score}

Baseline data at 0 week revealed the lequesne index as shown in Table 1. Highest $(12.68 \pm 2.23)$ was found in second group (Glucosamine sulphate with celecoxib) and the lowest $(9.13 \pm 2.47)$ was with diclofenac sodium treated group as compared within all groups. After the assigned treatments (Table 2), data was calculated at different time intervals and showed the highest percentage at $4^{\text {th }}$ week with combination of glucosamine sulphate and diclofenac sodium treated group $(47.70 \%)$ as compared with other treated groups respectively $(18.60 \% ; 14.27 \%$ and $31.65 \%)$ and similar data was also found to be at $2^{\text {nd }}$ week. Interesting results was obtained, diclofenac sodium treated group showed highest percentage $(31.65 \%)$, when we compared with celecoxib treated group and in combination of glucosamine sulphate with celecoxib treated group. Data was found to be statistical significant in all the groups.

\section{Visual Analogues Score}

At baseline data, (Table 3) Value revealed $5.22 \pm 1.44$ with the treated group (Combination of glucosamine with diclofenac sodium) than other combination (Glucosamine sulphate with celecoxib treated group), the value was $7.22 \pm 1.99$. After follow up treatments, the VAS score was in order of glucosamine sulphate with diclofenac sodium $>$ diclofenac sodium $>$ celecoxib $>$ glucosamine with celecoxib $(37.16 \%>31.05 \%>$ $24.87 \%>18.14 \%)$. The value was statistical higher significant difference between the treated groups.

\section{DISCUSSION}

Osteoarthritis is the most common among form of arthritis diseases. This is due to immovable joints at the onset of above 35 years but sometimes, it occurs at lower age of the patient also. ${ }^{32,33}$ Two guidelines $^{34,35}$ are available on the management of knee OA include European League Against Rheumatism (EULAR) and the American College of Rheumatology (ACR) indicated specific treatment suggested initially with physiotherapy, paracetamol and lifestyle advice and then adding further treatment in a step wise manner. The use of complementary medicine and therapies are growing in popularity in patients with knee 
osteoarthritis. Glucosamine sulphate and chondroitin sulphate are added drug therapy for the management of osteoarthritis. Drug prescription pattern study in Chinese population was conducted and suggested that combinational drug therapy showed adverse effect and the patterns of drug therapy were noticed that $16 \%$ were on glucosamine, $12 \%$ was on chondroitin and $14 \%$ was on non-steroidal anti inflammatory drug. ${ }^{36}$ Our findings indicated that, after one month treatment, Glucosamine sulphate with diclofenac sodium treated group and diclofenac sodium treated group showed much better results in terms of efficacy than other group which was celecoxib individual and in combination with glucosamine. Study demonstrated that both therapies show clinical improvement. Patients who received NSAID monotherapy shows more symptomatic relief during first two weeks whereas, glucosamine exerts its peak effect after 2 weeks of drug therapy.

According to ILAR classification, action of glucosamine was come under the category of symptomatic slow acting drugs in osteoarthritis ${ }^{35}$ NSAIDS may act as Inhibition of cyclooxygenase enzyme and prostaglandins synthesis. ${ }^{37}$ Efficacy and safety of NSAID's in osteoarthritis treatment has been reviewed in various studies. ${ }^{38-40}$ Many studies demonstrate that particular non selective COX inhibitors are as efficacious as selective COX-2 inhibitors (etoricoxib $60 \mathrm{mg} /$ day, valdecoxib $10 \mathrm{mg} /$ day) in pain relive. ${ }^{41-43}$ Chronic use of NSAID's can lead to increased risk of GI ${ }^{43,44}$ and renal complications. ${ }^{44}$ Selective COX-2 inhibitors like celecoxib are considered for use due to better GI tolerability. Whereas, one of the study demonstrated that canal treatment long term use of celecoxib showed increase the risk of Gastro intestinal bleeding up to $9 \%$ in root canal treatment ${ }^{45}$ and cardiovascular safety of COX-2 inhibitors is still challenging. ${ }^{46}$ Glucosamine sulphate, a derivative of the natural amino monosaccharide normally present in cartilage and synovial fluid of joints. Two randomized, controlled twofold blinded trials in Belgium ${ }^{26}$ and Czech Republic ${ }^{27}$ proposed that this medication ( $1.5 \mathrm{~g}$ day by day) has a considerable indication and structure changing impact in patients with mild to moderate osteoarthritis of knee. In a comparative study between glucosamine sulphate $(1,500 \mathrm{mg} /$ day $)$ and placebo, GS shows significant improvement in function parameters and pain. ${ }^{47}$ In a study, done in 200 hospitalized knee OA patients, GS was compared to traditional NSAID's. This study demonstrates same success rate between ibuprofen (1,200 mg) and GS (1,500 mg orally). After 4 weeks of therapy, success rate were 52

Table 1: Baseline Characteristics of patients between treatment groups.

\begin{tabular}{|c|c|c|c|c|c|}
\hline Variables & Celecoxib & $\begin{array}{c}\text { Glucosamine } \\
\text { sulphate }+ \\
\text { Celecoxib }\end{array}$ & $\begin{array}{l}\text { Diclofenac } \\
\text { sodium }\end{array}$ & $\begin{array}{c}\text { Glucosamine }+ \\
\text { Diclofenac sodium }\end{array}$ & Pvalue \\
\hline No. of patients & 90 & 90 & 90 & 90 & \\
\hline \multirow[t]{2}{*}{ Men/Women } & $26 / 64$ & $12 / 78$ & $14 / 76$ & $23 / 67$ & \\
\hline & $28.8 \% / 71.2 \%$ & $13.3 \% / 86.6 \%$ & $15.6 \% / 84.4 \%$ & $25.6 \% / 74.4 \%$ & \\
\hline Age (years) & $53.65 \pm 9.47$ & $58.77 \pm 9.04$ & $60.14 \pm 9.38$ & $51.44 \pm 8.76$ & $P<0.0001$ \\
\hline Age categories & & & & & $\mathrm{d}_{f}=359$ \\
\hline $31-40$ & 0 (M: 0, F: 0) & $3(\mathrm{M}=0, \mathrm{~F}=3)$ & $3(\mathrm{M}=1, \mathrm{~F}=2)$ & $3(\mathrm{M}=0, \mathrm{~F}=3)$ & $\mathrm{f}=18.25$ \\
\hline $41-50$ & $7(\mathrm{M}=1, \mathrm{~F}=6)$ & $9(\mathrm{M}=1, \mathrm{~F}=8)$ & $7(\mathrm{M}=1, \mathrm{~F}=6)$ & $15(\mathrm{M}=11, \mathrm{~F}=4)$ & \\
\hline $51-60$ & $61(M=13, F=48)$ & $58(\mathrm{M}=9, \mathrm{~F}=49)$ & $54(\mathrm{M}=6, \mathrm{~F}=48)$ & $55(\mathrm{M}=6, \mathrm{~F}=49)$ & \\
\hline $61-70$ & $22(\mathrm{M}=12, \mathrm{~F}=10)$ & $20(\mathrm{M}=2, \mathrm{~F}=18)$ & $26(\mathrm{M}=1, \mathrm{~F}=25)$ & $17(\mathrm{M}=3, \mathrm{~F}=14)$ & \\
\hline Body weight & $70.56 \pm 6.8$ & $73 \pm 5.34$ & $72.31 \pm 7.77$ & $75.40 \pm 6.10$ & $\begin{array}{c}P<0.0001 \\
\mathrm{~d}_{f}=359 \\
\mathrm{f}=8.39\end{array}$ \\
\hline \multicolumn{6}{|l|}{ Underlying disease, } \\
\hline Type-2 DM & 5 & 9 & 3 & 7 & \\
\hline Hypertension & 4 & 7 & 6 & 5 & \\
\hline Hypothyroidism & 0 & 1 & 0 & 0 & \\
\hline T2DM with HTN. & 22 & 10 & 7 & 7 & \\
\hline \multicolumn{6}{|l|}{ Localization } \\
\hline Left & 0 & 4 & 6 & 4 & \\
\hline Right & 12 & 10 & 9 & 11 & \\
\hline Bilateral & 78 & 76 & 75 & 75 & \\
\hline $\begin{array}{c}\text { Duration of } \\
\text { symptoms (months) }\end{array}$ & $3.11 \pm 1.04$ & $5.01 \pm 1.89$ & $4.1 \pm 1.03$ & $3.23 \pm 1.11$ & $\begin{array}{c}P<0.0001 \\
\mathrm{~d}_{f}=359 \\
\mathrm{f}=40.41\end{array}$ \\
\hline VAS & $8 \pm 2.25$ & $7.2 \pm 1.99$ & $6.15 \pm 1.90$ & $5.22 \pm 1.44$ & $\begin{array}{c}P<0.0001 \\
\mathrm{~d}_{f}=359 \\
\mathrm{f}=36.06\end{array}$ \\
\hline Lequesne index & $10.21 \pm 2.01$ & $12.68 \pm 2.23$ & $9.13 \pm 2.97$ & $9.79 \pm 2.47$ & $\begin{array}{c}P<0.0001 \\
\mathrm{~d}_{f}=359 \\
\mathrm{f}=36.14\end{array}$ \\
\hline
\end{tabular}


Table 2: Lequesne index at weekly intervals in different treated groups.

\begin{tabular}{ccccc} 
Week & Celecoxib & $\begin{array}{c}\text { Glucosamine } \\
\text { sulphate }+ \\
\text { Celecoxib }\end{array}$ & $\begin{array}{c}\text { Diclofenac } \\
\text { sodium }\end{array}$ & $\begin{array}{c}\text { Glucosamine } \\
\text { + Diclofenac } \\
\text { sodium }\end{array}$ \\
\hline $\mathbf{0}$ & $10.21 \pm 2.01$ & $12.68 \pm 2.23$ & $9.13 \pm 2.97$ & $9.79 \pm 2.47$ \\
2 & $9.16 \pm 1.22$ & $11.10 \pm 2.09$ & $7.43 \pm 2.24$ & $7.26 \pm 3.11$ \\
& $(10.28 \%)$ & $(12.46 \%)$ & $(18.61 \%)$ & $(25.84 \%)$ \\
\multirow{4}{*}{ P value } & $8.31 \pm 2.99$ & $10.87 \pm 2.88$ & $6.24 \pm 2.31$ & $5.12 \pm 2.99$ \\
& $(18.60 \%)$ & $(14.27 \%)$ & $(31.65 \%)$ & $(47.70 \%)$ \\
& $P<0.0001$ & $P<0.001$ & $P<0.001$ & $P<0.001$ \\
& $f=20.18$, & $f=14.86$ & $f=29.70$ & $f=59.70$ \\
& $\mathrm{~d}_{f}=269$ & $\mathrm{~d}_{f}=269$ & $\mathrm{~d}_{f}=269$ & $\mathrm{~d}_{f}=269$ \\
\hline
\end{tabular}

Table 3: Visual analogue scales at weekly intervals in different treated groups.

\begin{tabular}{ccccc} 
Week & Celecoxib & $\begin{array}{c}\text { Glucosamine } \\
\text { sulphate }+ \\
\text { Celecoxib }\end{array}$ & $\begin{array}{c}\text { Diclofenac } \\
\text { sodium }\end{array}$ & $\begin{array}{c}\text { Glucosamine } \\
\text { + Diclofenac } \\
\text { sodium }\end{array}$ \\
\hline 0 & $8 \pm 2.25$ & $7.22 \pm 1.99$ & $6.15 \pm 1.90$ & $5.22 \pm 1.44$ \\
2 & $7.05 \pm 1.54$ & $6.01 \pm 1.43$ & $5.35 \pm 1.73$ & $4.18 \pm 1.65$ \\
& $(11.87 \%)$ & $(16.75 \%)$ & $(13.0 \%)$ & $(19.92 \%)$ \\
4 & $6.01 \pm 1.50$ & $5.91 \pm 1.95$ & $4.24 \pm 1.75$ & $3.28 \pm 1.64$ \\
& $(24.87 \%)$ & $(18.14 \%)$ & $(31.05 \%)$ & $(37.16 \%)$ \\
P value & $P<0.0001$ & $P<0.001$ & $P<0.001$ & $P<0.001$ \\
& $f=27.62$ & $f=14.63$ & $f=28.42$ & $f=33.99$ \\
& $\mathrm{~d}_{f}=269$ & $\mathrm{~d}_{f}=269$ & $\mathrm{~d}_{f}=269$ & $\mathrm{~d}_{f}=269$ \\
\hline
\end{tabular}

$\%$ for ibuprofen and $48 \%$ for GS. Ibuprofen onset of effect occurs sooner than that of GS, with the success rate of $48 \%$ for ibuprofen and $28 \%$ for GS.$^{48}$ In our study, pattern of drug response was similar to this study. Our study demonstrates lesser significant difference in improvement between selective COX-2 inhibitors monotherapy and glucosamine plus selective COX-2 inhibitors after 2 weeks of therapy. After 4 weeks, patients who were on glucosamine plus selective COX-2 inhibitors show more improvement and decrease in lequesne scores as compared to selective COX-2 inhibitor monotherapy. This pattern of drug response was also favoured by another study done in 68 Chinese patients with knee OA and no significant difference was observed between GS and ibuprofen in terms of symptoms relieve. This study also demonstrates better GI tolerability of GS as compared to ibuprofen. ${ }^{49,50}$ Another study conducted and demonstrates that those patients who received GS therapy showed a significant decrease in pain measured by visual analogue scale in different time intervals and suggested to prescribe in large population. ${ }^{51}$ Similar results were found in Thai population which shows that monotherapy of glucosamine improves pain by WOMAC score as compared with combination therapy diacerin and glucosamine. ${ }^{52}$ Over all, drug therapy prescribed by the physician that depend upon the patient condition whether they need combinational or monotherapy. The main limitation is to control the adverse effects of NSAIDS drugs.

\section{CONCLUSION}

From the study, it can be concluded that both monotherapy of NSAID's and co-administration of glucosamine with NSAID's can significantly reduce lequesne score and VAS score in patients with Knee osteoarthritis. Moreover, when glucosamine sulphate was combined with NSAID's, impact on lequesne index was found to be more profound, especially when glucosamine was co-administered with non-selective COX inhibitors whereas similar results were also observed in VAS scores.

\section{CONFLICT OF INTEREST}

The authors declare no conflict of interest.

\section{ABBREVIATIONS}

ACR: American College of Rheumatology; Cox-2I: Cyclooxegenase-2 inhibitors; EULAR: European League Against Rheumatism; ILAR: International League against Rheumatism; LI: Lequesne index; NSAIDS: Non Steroidal Anti inflammatory Drugs; SD: standard deviation; VAS:Visual Analogues Score; WOMAC: Western Ontario and McMaster Universities Osteoarthritis Index.

\section{REFERENCES}

1. Essex MN, O'Connell MA, Behar R, BAO W. Efficacy and safety of non steroidal anti-inflammatory drugs in Asian patients with knee osteoarthritis: Summary of a randomized, placebo-controlled study. Intern J Rheumat Diseas. 2016;19(3):262-70.

2. Silman AJ, Hochberg MC. $2^{\text {nd }}$ ed. Oxford: Oxford University Press Epidemiol Rheumat Diseas. 2001.

3. Ebell MH. Osteoarthritis: Rapid Evidence Review. Am Fam Physician. 2018;97(8):523-6.

4. Haq I, Murphy E, Dacre J. Osteoarthritis. Postgrad Med J. 2003;79:377-83.

5. Akinpelu AO, Alonge TO, Adekanla BA, Odole AC. Prevalence and pattern of symptomatic knee osteoarthritis in Nigeria: A community-based study. Internet J Allied Health Sci Pract. 2009;7(3):10.

6. Symmons D, Mathers C, Pfleger B. Global Burden of Osteoarthritis in year 2000: Global burden of disease 2000 study. World Health Report. 2002;5:2.

7. Mandl LA. Osteoarthritis year in review 2018: Clinical. Osteoarthritis Cartilage. 2019;27(3):359-64.

8. Lozano R, Naghavi M, Foreman K, Lim S, et al. Global and regional mortality from 235 causes of death for 20 age groups in 1990 and 2010: A systematic analysis for the Global Burden of Disease Study 2010. Lancet. 2012;380(9859):2095-128.

9. Wolf AD, Pfleger B. Burden of Major Musculoskeletal Conditions. Policy and Practice. Special Theme Bone and Joint Decade 2000-2010. Bull World Health Organ. 2003;81:646-56

10. Ganvir SD, Zambare BR. Prevalence and Identification of Risk Factors for Knee Osteoarthritis among Elderly Men and Women. Sch J App Med Sci. 2013;1(6):700-3

11. Jordan KM, Arden NK, Doherty $M$, Bannwarth $B$, et al. EULAR Recommendations 2003: An Evidence Based Approach to the Management of Knee Osteoarthritis: Report of a Task Force of the Standing Committee for International Clinical Studies Including Therapeutic Trials (ESCISIT). Ann Rheum Dis. 2003;62(12):1145-55

12. Pal CP, Singh P, Chaturvedi S, Pruthi KK, Vij A. Epidemiology of knee osteoarthritis in India and related factors. Indian J Orthop. 2016;50:518-22.

13. Venkatachalam J, Natesan M, Eswaran M, Jhonson ASM, Bharath V, Singh Z. Prevalence of osteoarthritis of knee joint among adult population in a rural area of Kanchipurum district Tamil Nadhu. Ind J Pub Healt. 2018;62(2):117-22.

14. Hinman RS, Bennel K, Metcalf B, Crossley K. Delayed onset of quadriceps activity and altered knee joint kinematics during stair stepping in individuals with knee osteoarthritis. Arch Phys Med Rehabil. 2002;83(8):1080-6.

15. Gregori D, Giacovelli G, Minto C et al. Association of Pharmacological Treatments With Long-term Pain Control in Patients With Knee Osteoarthritis: A Systematic Review and Meta-analysis. JAMA. 2018;320(24):2564-79. doi:10.1001/jama.2018.19319

16. Ringdahl E, Pandit S. Treatment of knee osteoarthritis. Am Fam Physician. 2011;83(11):1287-92

17. Wegman A, VanderWD, VanTM, Stalman W, Devries T. NSAID or acetaminophen for osteoarthritis of hip or knee: A systemic review of evidence and guidelines. Rheumatol 2004;31:199-202.

18. Bell G M, Schnitzer TJ. Cox-2 inhibitors and other nonsteroidal anti-inflammatory drugs in the treatment of pain in the elderly. Clin Geriatr Med. 2001;17(3):489 502.

19. Matusumoto A K, Cavanaugh PF. Etoricoxib. Drugs Toda. 2004;40(5):395-414

20. Fenton C, Keating GM, Wagstaff AJ. Valdecoxib: A review of its use in management of osteoarthritis, rheumatoid arthritis, dysmenoulique and acute pain. Drugs. 2004;64:1231-61.

21. Graham DJ, Campen D, Hui R, Spence M, Cheetham C. Risk of acute myocardial infarction and sudden cardiac death in patients treated with cyclooxygenase 2 selective and non-selective, non-steroidal anti-inflammatory drugs: Nested case control study. Lancet. 2005;365(9458):475-81. 
22. Serni U. Profile of glucosamine sulfate as an example of Slow Acting Drug in Osteoarthritis. In: Proceedings of the XVIIIth ILAR Congress of Rheumatology. Rev Esp Reumatol. 1993;222.

23. Avouac B. Slow Acting Drugs in osteoarthritis of the XVHI th ILAR Congress of Rheumatology. Rev Esp Reumatol. 1993;221-2.

24. Bassleer C, Henrotin Y, Franchimont P. In-vitro evaluation of drugs proposed as chondroprotective agents. Int J Tissue React. 1992;14:231-41.

25. McColl G. Glucosamine for osteoarthritis of the knee. Aust Presc. 2004;27:61-3.

26. Reginster JY, Deroisy R, Rovati LC, et al. Long-term effects of glucosamine sulphate on osteoarthritis progression: A randomised, placebo-controlled clinical trial. Lancet. 2001;357(9252):251-6.

27. Pavelka K, Gatterova J, Olejarova M. Glucosamine sulfate use and delay of progression of knee osteoarthritis: A 3-year, randomized, placebo-controlled, double-blind study. Arch Intern Med. 2002;162(18):2113-23.

28. Leeb BF, Schweitzer H, Montag K, Smolen JS. A metaanalysis of chondroitin sulfate in the treatment of osteoarthritis. J Rheumatol. 2000;27:205-11.

29. McAlindon TE, LaValley MP, Gulin JP, Felson DT. Glucosamine and chondroitin for treatment of osteoarthritis: A systematic quality assessment and metaanalysis. JAMA. 2000;283(11):1469-75.

30. Richy F, Bruyere O, Ethgen O, Cucherat M, Henrotin Y, Reginster JY. Structural and symptomatic efficacy of glucosamine and chondroitin in knee osteoarthritis: A comprehensive meta-analysis. Arch Int Med. 2003;163(13):1514-22.

31. Lequesne MG. The algofunctional indices for hip and knee osteoarthritis. J Rheumatol. 1997;24(4):779-81.

32. O'NeillTW, Felson DT. Mechanisms of Osteoarthritis (OA) Pain. Curr Osteoporos Rep. 2018;16(5):611-6. doi:10.1007/s11914-018-0477-1

33. Sacitharan PK. Ageing and Osteoarthritis. Subcell Biochem. 2019;91:123-59. Doi: 10.1007/978-981-13-3681-2_6

34. Jordan KM, Sawyer S, Coakley P, Smith HE, Cooper C, Arden NK. The use of conventional and complimentary treatments for knee osteoarthritis in the community. Rheumatology. 2004;43(3):381-4.

35. Lequesne M. ILAR guidelines for testing Slow Acting Drugs in Osteoarthritis (SADOAs). In: Proceedings of the XVIIIth ILAR Congress of Rheumatology. Rev Esp Rheumatic. 1993;20(suppl 1):220-1.

36. Wang F, Wang Y, Xing H, Xu L, Zhou J. Drug Prescription patterns in osteoarthritis patients in a tertiary care hospital in China. Indian J Pharm Sci. 2019;81(3):55561.

37. Abramson SB, Weismann G. The mechanism of action of nonsteroidal anti inflammatory drugs. Arthritis Rheum. 1989;32:1-9.

38. Lewis AJ, Furst DE. Nonsteroidal anti-inflammatory drugs: Mechanisms and clinical use. New York, NY: Marcel Dekker. 1987.
39. Bollet AJ. Analgesic and anti-inflammatory drugs in the therapy of osteoarthritis. Semin Arthritis Rheum. 1981;11(1):130-2.

40. Paulus HE, Furst DE, Dromgoole SH. Drugs for Rheumatic Disease. New York, NY: Churchill Livingstone. 1987.

41. Schlegel S, Paulus H. Update on NSAID use in rheumatic diseases. Bull Rheum Dis. 1986;36:1-8.

42. Matusumoto AK, JrCavanaughr PF. Etoricoxib. Newer Cox-2 inhibitor. Drugs Today BARC. 2004;40:395-414.

43. Fenton C, Keating GM, Wagstaff AJ. Valdecoxib: A review of its use in management of osteoarthritis, rheumatoid arthritis, dysmenoulique and acute pain. Drugs. 2004;64:1231-61.

44. Temple A, Benson G, Zinsenheim J. Multicenter, randomized, double-blind, active-controlled, parallel-group trial of the long-term (6-12 months) safety of acetaminophen in adult patients with osteoarthritis. Clin Ther. 2006;28(2):22235.

45. Sawitzke A, Shi H, Finco M. Clinical efficacy and safety of glucosamine, chondroitin sulphate, their combination, celecoxib or placebo taken to treat osteoarthritis of the knee: 2-year results from GAIT. Ann Rheum Dis. 2010;69(8):1459-64

46. Cutolo M, Berenbaum F, Hochberg M. Commentary on recent therapeutic guidelines for osteoarthritis. Semin Arthritis Rheum. 2015;44(6):611-7.

47. Graham DJ, Campen D, Hui R. Risk of acute myocardial infarction and sudden cardiac death in patients treated with cyclooxygenase 2 selective and nonselective, non-steroidal anti-inflammatory drugs: Nested case control study. Lancet. 2005;365(9458):475-81.

48. Rovati L. Clinical efficacy of glucosamine sulfate in osteoarthritis of the spine Rev Esp Reumatol. 1993; 20(S1):325.

49. Muller-Fassbender H, Bach GL, Haase W, Rovati LC, Setnikar I. Glucosamine sulfate compared to ibuprofen in osteoarthritis of the knee. Osteoarthr Cartil. 1994;2(1):61-9.

50. Qiu GX, Gao SN, Giacovelli G, Rovati L, Setnikar I. Efficacy and safety of glucosamine sulfate versus ibuprofen in patients with knee osteoarthritis. Arzneimittel Forschung. 1998;48(5):469-74.

51. Tenti S, Giordano N, Mondanelli N, Giannotti S, Maheu E, Fioravanti A. A retrospective observational study of glucosamine sulfate in addition to conventional therapy in hand osteoarthritis patients compared to conventional treatment alone. Aging Clin Exp Res, 2020; 32:1161-1172.

52. Kongtharvonskul J, Woratanarat $P$, McEvoy $M$, Attia J, Wongsak $S$

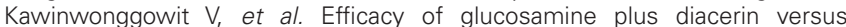
montherapy of glucosamine: A double-blind, parallel randomized clinical trial. Arthritis Res Ther. 2016;18(1):233.

Article History: Submission Date : 20-05-2020; Revised Date : 18-07-2020; Acceptance Date : 28-08-2020

Cite this article: Arora A, Kumari R, Gupta S, Singh M. Prospective study in tertiary care hospital for osteoarthritis patients in rural area of Haryana. J Young Pharm. 2020;12(3):275-9. 